\title{
Helicobacter Pylori Associated Gastritis Increases Risk of Colorectal Polyps: a Hospital Based-Cross-Sectional Study in Nakhon Ratchasima Province, Northeastern Thailand
}

\author{
Taweesak Tongtawee ${ }^{1,4 *}$, Soraya Kaewpitoon ${ }^{2,4}$, Natthawut Kaewpitoon ${ }^{5,6}$, \\ Chavaboon Dechsukhum ${ }^{3,4}$,Wilairat Leeanansaksiri ${ }^{5}$, Ryan A Loyd ${ }^{2,4}$, Likit \\ Matrakool $^{1,4}$, Sukij Panpimanmas ${ }^{1,4}$
}

\begin{abstract}
Background: Colorectal polyps are common in Thailand, particularly in the northeastern region. The present study aimed to determine any correlation between Helicobacter pylori-associated gastritis and colorectal polyps in the Thai population. Materials and Methods: A total of 303 patients undergoing esophagogastroduodenoscopy with colonoscopy for investigation of chronic abdominal pain participated in this study from November 2014 to October 2015. A diagnosis of Helicobacter pylori associated gastritis was made if the bacteria were seen on histopathological examination and a rapid urease test was positive. Colorectal polyps were confirmed by histological examination of colorectal biopsies. Patient demographic data were analyzed for correlations. Results: The prevalence of colorectal polyps was $77(25.4 \%)$, lesions being found more frequently in Helicobacter pylori infected patients than non-infected subjects [38.4\% vs. 12.5\%; Odds Ratio (OR) (95\% CI): 2.26 (1.32 - 3.86), p < 0.01]. Patients with Helicobacter pylori - associated gastritis were at high risk of having adenomas featuring dysplasia [OR $(95 \% \mathrm{CI}): 1.15(1.16-7.99) ; \mathrm{P}=0.02]$. There was no varaition in location of polyps, age group, sex and gastric lesions with respect to Helicobacter pylori status. Conclusions: This study showed that Helicobacter pylori associated gastritis is associated with an increased risk of colorectal polyps, especially adenomas with dysplasia in the Thai population. Patients with Helicobacter pylori-associated gastritis may benefit from concurrent colonoscopy for diagnosis of colorectal polyps as a preventive and early treatment for colorectal cancer.
\end{abstract}

Keywords: Helicobacter pylori-associated gastritis - colorectal polyps - dysplasia - risk factor

Asian Pac J Cancer Prev, 17 (1), 341-345

\section{Introduction}

Colorectal cancer $(\mathrm{CRC})$ is the third most cancer in males and the second most common cancer in females in the US (William et al., 2015). The incidence of CRC is related to both genetic and environmental factors. Many studies suggest dietary habits alcohol intake, inactive lifestyle, smoking, obesity and family history of colorectal cancer as possible risk factors for developing CRC but geographically there are differences among countries (Hsing et al., 1998; Ganesh et al., 2009; Wang et al., 2010; De Stefani et al., 2012; Durko and Malecka-Panas, 2014).

CRC data was reported from the National Cancer Institute of Thailand from 1990 to 2005 tinding that colorectal cancer (CRC) was the third and fifth most common cancer in men and women (National Cancer Institute, 2012). Screening colonoscopy is the way to reduce the incidence of advanced $\mathrm{CRC}$ and cancer-related mortality. Screening colonoscopies from a large single center of Thailand, showed that, the incidence of colorectal polyps is $30.6 \%$ (Left-sided is $45.1 \%$, right-sided colon is $36.5 \%$ and the rectum is $18 \%$ ) (Pitulak et al., 2012). The prevalence of Helicobacter pylori infection varies between different countries and geographic locations, including Thailand. Among different geographic locations in Thailand, the prevalence of Helicobacter pylori infection in the South region of Thailand $(14.4 \%)$ was the lowest, compared with the Northeast (60.6\%), North (46.9\%), and Central (39.0\%) regions (all $\mathrm{p}<0.001)$ (Uchida, 2015).

The role of Helicobacter pylori infection in colorectal cancer development remains unclarified (Zumkeller et al., 2012). Several studies tried to investigate and describe this role but there is no data in Thai population. One study from Thailand identified risk factors for colorectal cancer in the Thai population. The result showed, no 
evidence of environmental factors affecting the risk of CRC (Kirati Poomphakwaen et al., 2015). In a study among 2,195 eligible subjects, the results showed that, the prevalence of colorectal adenoma and advanced adenoma was significantly higher in the Helicobacter pylori positive group (25.3 vs. $20.1 \%$, p=0.004 and 6.1 vs. $2.9 \%, \mathrm{p}<0.001$, respectively) (Hong SN et al., 2012). Helicobacter pylori infection, including CagA expression is associated with an increased risk for the development of colonic neoplasm (OR=2.73,95\% CI: 1.76-4.24) (Selgrad et al., 2014). A meta-analysis suggests a promoting effect of Helicobacter pylori on the risk of adenocarcinoma and adenomatous polyps. It also suggests that Helicobacter pylori infection might have its influence at the start of the adenomatous polyp disease sequence (OR 1.24, 95\% CI 1.12-1.37, $\mathrm{P}=0.66$; OR 1.87, 95\% CI 1.53-2.28, $\mathrm{P}=0.81$ ) (Wang et al., 2014) and some studies suggest that, Helicobacter pylori infection is associated with the development of advanced colorectal neoplasia (OR 7.98; 95\% CI 3.16-20.16; p<0.001) (Shmuely et al., 2014). We are interested in pursuing clinical study in the Thai population to evaluate the possible association between Helicobacter pylori associated gastritis and the prevalence of colorectal polyps.

\section{Materials and Methods}

\section{Patients}

303 patients undergoing esophagogastroduodenoscopy with colonoscopy for investigation of chronic abdominal pain participated in this study from November 2014 to October 2015. The study was performed in accordance with good clinical practice and the guidelines of the Declaration of Helsinki. All patients provided written informed consent and the study protocol was approved by the Ethics Committee for Research Involving Human
Subjects, Suranaree University of Technology (EC-57-34).

Diagnosis of Helicobacter pylori associated gastritis

A diagnosis of Helicobacter pylori infection was made if Helicobacter pylori morphology was seen on histopathological examination and the rapid urease test during gastroscopy was positive. Patients with negative results in one or both examinations were considered to be H. pylori negative.

\section{Biopsy specimens}

The gastroscopic procedures were performed using an upper GI video endoscope (Olympus EVIS EXERA III, CV-190). The whole stomach was examined first with conventional endoscopy. After the whole stomach mucosa was observed we then chose sites for biopsy of the gastric mucosa according to previous studies (Taweesak et al., 2015)

\section{Histological analysis}

Gastric tissue and terminal ileum specimens were sent to the pathologists for histological analysis. The hematoxylin and eosin stain and the Giemsa stain were used for identification of Helicobacter pylori. The pathological analysis was made by 5 pathologists at Bangkok Pathological Laboratory outside of Suranaree University of Technology.

\section{Statistical analysis}

We used univariate analysis to compare the distribution of variables between Helicobacter pylori positive and negative subjects. Then we computed unadjusted Odds Ratio (OR) (95\% Confidence Interval [CI]) for potential predictors of colorectal polyps. Multivariate logistic regression analysis was applied to compute the adjusted OR $(95 \% \mathrm{CI})$ for predictors of colorectal polyps. The final

Table 1. Distribution of clinical variables and $H$. pylori infection (univariate analysis)

\begin{tabular}{|c|c|c|c|}
\hline & $\begin{array}{l}\text { Positive for } H \text {. pylori n }(\%) \\
\text { Total number: } 151\end{array}$ & $\begin{array}{c}\text { Negative for } H . \text { pylori n }(\%) \\
\text { Total number: } 152\end{array}$ & p-Value* \\
\hline Age group & & & 0.99 \\
\hline $17-30$ years & $24(15.89 \%)$ & $26(17.10 \%)$ & \\
\hline $31-44$ years & $46(30.46 \%)$ & $51(33.55 \%)$ & \\
\hline $45-58$ years & $50(33.11 \%)$ & $47(30.92 \%)$ & \\
\hline $59-70$ years & $31(20.52 \%)$ & $28(18.42 \%)$ & \\
\hline Sex (male/female) & $55 / 96$ & $61 / 93$ & 0.72 \\
\hline Gastric lesions & & & $<0.01 *$ \\
\hline No gastric lesion & $9(5.96 \%)$ & $108(71.05 \%)$ & \\
\hline Chronic Active Gastritis & $101(66.88 \%)$ & $29(19.07 \%)$ & \\
\hline Gastric ulcer & $32(21.19 \%)$ & $12(7.89 \%)$ & \\
\hline Intestinal metaplasia & $5(3.31 \%)$ & $2(1.31 \%)$ & \\
\hline Gastric cancer & $4(2.64 \%)$ & $1(0.65 \%)$ & \\
\hline Polyp n (\%) & $58(38.41 \%)$ & $19(12.50 \%)$ & $<0.01 *$ \\
\hline Polyp Histology & & & $<0.01 *$ \\
\hline Hyperplastic polyp & $28(48.27 \%)$ & $14(73.68 \%)$ & \\
\hline Adenoma without dysplasia & $19(32.75 \%)$ & $3(15.78 \%)$ & \\
\hline Adenoma with dysplasia & $11(18.96 \%)$ & $2(10.52 \%)$ & \\
\hline Polyp Location & & & $<0.01 *$ \\
\hline Right side & $8(13.79 \%)$ & $4(21.05 \%)$ & \\
\hline Left side & $31(53.44 \%)$ & $11(57.89 \%)$ & \\
\hline Both sides & $14(24.13 \%)$ & $2(10.52 \%)$ & \\
\hline
\end{tabular}

*Significance is set at $\mathrm{p}<0.05$. 
model was developed with a stepwise backward approach. All variables with $\mathrm{P}<0.05$ were considered statistically significant and remained in the final model. All analyses were done using SPSS 16.0 (SPSS Inc., IL).

\section{Results}

A total of 303 patients enrolled in this study. Male $116(38.3 \%)$ and female 187 (61.7\%). All subjects went through complete esophagogastroduodenoscopy with colonoscopy. The prevalence of Helicobacter pylori infection and colorectal polyps were $49.83 \%$ and $25.41 \%$ respectively. There were total of 303 gastric "mucosal biopies" including 117 no gastric lesion, 130 chronic active gastritis, 44 gastric ulcer, 7 intestinal metaplasia and 5 gastric cancer. Helicobacter pylori associated gastritis was positive in $49.83 \%$ of cases. The majorities were age group $45-58$ years old $(33.11 \%)$, female $(65.56 \%)$ respectively. A total of 77 colorectal polyps were found including 42 hyperplastic polyps, 22 adenomas without dysplasia and 13 adenomas with dysplasia. In terms of polyp location, 14 polyps were located at the right side, 42 polyps were located at the left side and 16 polyps were

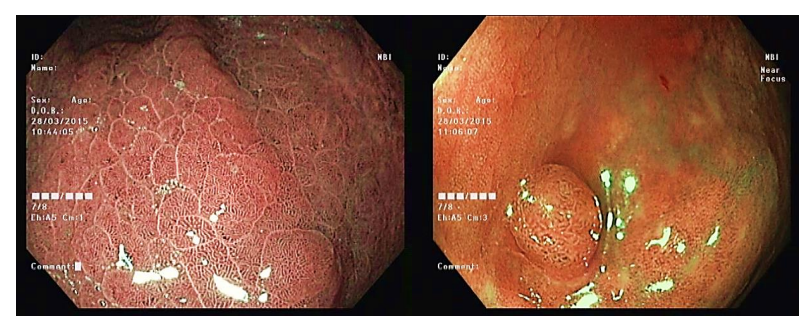

Figure 1. Endoscopic Picture of $\boldsymbol{H}$. pylori-associated Gastritis [1] and Hyperplastic Polyp [2] in the Same Patient

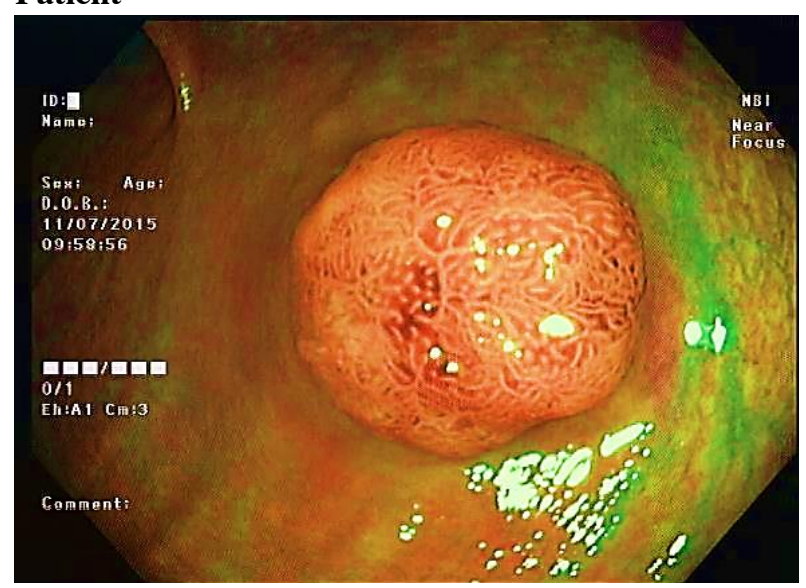

Figure 2. Endoscopic Picture of $\boldsymbol{H}$. pylori-associated Gastritis and Polyp without Dysplasia

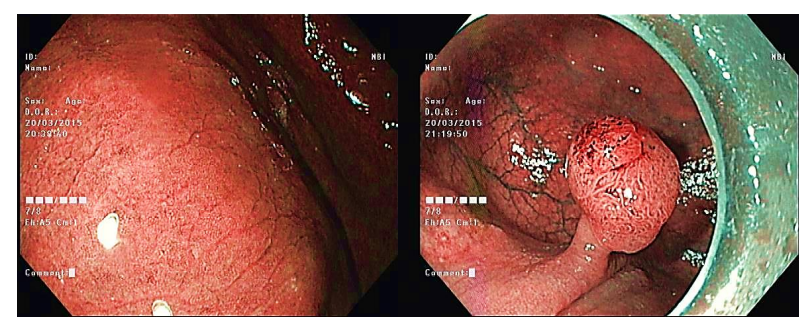

Figure 3. Endoscopic Picture of $\boldsymbol{H}$. pylori-associated Gastritis [1] and Polyp with Dysplasia [2] in the Same Patient
Table 2. Multivariate Logistic Regression for Predictors of Clinical Variables and $\boldsymbol{H}$. pylori infection

\begin{tabular}{lccc}
\hline Variable & Oddsratio & $\begin{array}{c}95 \% \\
\text { Confidence } \\
\text { interval }\end{array}$ & P* \\
& & & \\
\hline Gastric lesions & & $0.04-0.37$ & $<0.01^{*}$ \\
Chronic Active Gastritis & 0.04 & $0.09-8.09$ & 0.90 \\
Gastric ulcer & 0.87 & $0.06-6.58$ & 0.72 \\
Intestinal metaplasia & 0.66 & $0.04-9.65$ & 0.73 \\
Gastric cancer & 0.62 & $1.32-3.86$ & $<0.01 *$ \\
Polyp & 2.26 & & \\
Polyp Histology & & $0.03-0.66$ & $0.01 *$ \\
Hyperplastic polyp & 0.14 & $0.07-1.87$ & 0.22 \\
Adenoma without dysplasia & 0.36 & $1.16-7.99$ & $0.02 *$ \\
Adenoma with dysplasia & 1.15 & & \\
Polyp Location & & $0.18-1.11$ & 0.08 \\
Right side & 0.44 & $0.31-1.44$ & 0.60 \\
Left side & 1.52 & $0.38-3.18$ & 0.85 \\
Both sides & 1.10 & &
\end{tabular}

*Significance is set at $\mathrm{p}<0.05$.

located at both sides. There were significant differences in gastric lesions, polyp number, polyp histology, polyp location and isolated terminal ileitis $(\mathrm{p}<0.01)$. The Distribution of clinical variables and Helicobacter pylori infection by using univariate analysis are summarized in Table 1. Among the distribution of clinical variables, there were no significant differences in sex and age group ( $\mathrm{p}>0.05$ ). Multivariate logistic regression for predictors of clinical variables and Helicobacter pylori infection revealed significant differences in polyp number and polyp histology (adenoma with dysplasia) [(OR $2.26,95 \%$ CI 1.32 - 3.86, p<0.01), ( OR 1.15, 95\%CI 1.16$7.99, \mathrm{p}=0.02)]$.The multivariate logistic regressions for predictors of clinical variables and Helicobacter pylori infection are summarized in Table 2.The endoscopic pictures of Helicobacter pylori associated gastritis and colorectal polyp in the same patient during endoscopy are as shown in Figure 1 though Figure 3.

\section{Discussion}

Helicobacter pylori infection in humans is associated with a spectrum of gastroenterologic and hematologic diseases including chronic gastritis, peptic ulcers, gastric adenocarcinoma, gastric mucosa-associated lymphoid tissue lymphoma, sideropenic anemia and primary immune thrombocytopenia. It is may also increased the risk for colorectal polyps and colorectal carcinoma. Several studies tried to investigate the association between colorectal cancer and Helicobacter pylori infection particularly (Hong et al., 2012; Selgrad et al., 2014; Shmuely et al., 2014; Wang et al., 2014), but there is limited data in the Thai population. In a meta-analysis in 2006, a summary odds ratio of 1.4 (95\% CI, 1.1-1.8) was estimated for the association between Helicobacter pylori infection and colorectal cancer risk (Zumkeller et al., 2006). In a meta-analysis in 2007, the results showed a significantly increased risk for tubular adenomas $(\mathrm{OR}=11.13 ; 95 \% \mathrm{CI}=1.62-76.70)$, tubulovillous adenomas $(\mathrm{OR}=10.45 ; 95 \% \mathrm{CI}=1.52-71.52)$ and adenocarcinomas $(\mathrm{OR}=8.13 ; 95 \% \mathrm{CI}=1.40-46.99)$ compared to controls 
(Jones et al., 2007) and in a meta-analysis in 2008, a summary OR 1.49 (95\% confidence interval [CI] 1.17-1.91) was estimated for the association between Helicobacter pylori infection and colorectal cancer (Zhao et al., 2008). Several studies tried to describe the correlation between Helicobacter pylori infection and colorectal neoplasm. Three hypotheses have been proposed. First is the hypergastrinemia hypothesis, A study in 1995 about the expression, processing, and secretion of gastrin in patients with colorectal carcinoma, showed that, gastrin should continue to be assessed as a circulating or autocrine growth factor in the development of CRC (fasting plasma total gastrin levels were increased in Helicobacter pylori positive (5.2-fold) and Helicobacter pylori negative (2.3-fold) patients with CRC) (Ciccotosto et al., 1995). In a prospective study in 1998, the authors concluded that, hypergastrinemia is associated with an increased risk of colorectal carcinoma (odds ratio, 3.9; 95\% confidence interval, 1.5-9.8) (Thorburn et al., 1998) and in a prospective case-controled study in 2006 , the authors concluded that, hypergastrinemia is a risk factor for colon cancer, especially of the distal colon (odds ratio 3.2, 95\% CI 1.4-7.5) (Georgopoulos, 2006) whereas others studies found no correlation (Penman et al., 1994; Fireman et al., 2000).

Second is the intestinal flora changing hypothesis, In a study about the fecal floras of polyp patients, the results showed, the overgrowth of Bacteroides species to be highly associated with a high risk of colon cancer (Moore, 1995; Horie et al., 1999; Kado, 2001). Hypochlorhydria status is associated with intestinal bacterial overgrowth (Drasar, 1969; Howden, 1987; Thorens, 1996). Helicobacter pylori infection causes chronic gastritis gastric gland atrophy and hypochlorhydric status. Several studies tried to describe association between hypochlorhydric status and colorectal cancer. Hypochlorhydric status leads to mulabsorption of proteins and promotes bacterial fermentation in the large intestine which may be an etiology of colonic malignancy (Aarbakke, 1976; Visek, 1978).

Third is the inflammation mediated hypothesis, in a study in 2000 , the results showed that, IL-8 acts as an autocrine growth factor for colon carcinoma cell lines (Brew, 2000). In a study of the relationship between Helicobacter pylori CagA status and colorectal cancer in 2001, the results showed that, Helicobacter pylori, CagA+ seropositivity is associated with increased risk for both gastric and colonic cancer (odds ratio $=10.6$; 95\% CI=2.741.3; $\mathrm{p}=0.001$ ) (Shmuely, 2001).

A cross-sectional hospital-based study in 2010, showed that, Helicobacter pylori infection with concomitant metabolic syndrome might further increase the risk of colorectal adenomas (OR: 1.408, 95\% CI: 1.231-1.610, $\mathrm{P}<0.001)$ (Lin, 2010). Our study has demonstrated the significant correlation of Helicobacter pylori infection and the prevalence of colorectal polyps especially adenomas with dysplasia in the Thai population (OR: 2.26, 95\% CI: 1.32 - 3.86, P<0.001; OR: 1.15, 95\% CI: 1.16 - 7.99 , $\mathrm{P}=0.02$ ). This sentence repeats the previous sentence exactly and you can probably erase it. Patients with Helicobacter pylori associated gastritis may benefit from concurrent colonoscopy for the diagnosis of colorectal polyps as a preventative and early treatment for colorectal cancer.

\section{Acknowledgements}

This study was supported by a grant for medical investigation from Suranaree University of Technology and was approved by the Ethics Committee for Research Involving Human Subjects Suranaree University of Technology (EC-57-34).

\section{References}

Aarbakke J, Schjönsby H (1976). Value of urinary simple phenol and indican determinations in the diagnosis of the stagnant loop syndrome. Scand J Gastroenterol, 11, 409- 14.

Brew R, Erikson JS, West DC, et al (2000). Interleukin-8 as an autocrine growth factor for human colon carcinoma cells in vitro. Cytokine, 12, 78-85.

Ciccotosto GD, McLeish A, Hardy KJ, et al (1995). Expression, processing, and secretion of gastrin in patients with colorectal carcinoma. Gastroenterol, 109, 1142- 53.

De Stefani E, Ronco AL, Boffetta P, et al (2012). Nutrient derived dietary patterns and risk of colorectal cancer: a factor analysis in Uruguay. Asian Pac J Cancer Prev, 13, 231-5.

Drasar BS, Shiner M, McLeod M, et al (1969). Studies on the intestinal flora. I. The bacterial flora of the gastrointestinal tract in healthy and achlorhydric persons. Gastroenterol, 56, 71-9.

Durko L, Malecka-Panas E (2014). Lifestyle Modifications and Colorectal Cancer. Curr Colorectal Cancer Rep, 10, 45-54.

Fireman Z, Trost L, Kopelman Y, et al (2000). Helicobacter pylori: seroprevalence and colorectal cancer. Isr Med Assoc $J, 2,6-9$.

Ganesh B, Talole SD, Dikshit R (2009). A case-control study on diet and colorectal cancer from Mumbai, India. Cancer Epidemiol, 33, 189-93.

Georgopoulos SD, Polymeros D, Triantafyllou K, et al (2006). Hypergastrinemia is associated with increased risk of distal colon adenomas. Digest, 74, 42-6.

Horie H, Kanazawa K, Okada M, et al (1999). Effects of intestinal bacteria on the development of colonic neoplasm: an experimental study. Eur J Cancer Prev, 8, 237-45.

Hong SN, Lee SM, Kim JH, et al (2012). Helicobacter pylori infection increases the risk of colorectal adenomas: crosssectional study and meta-analysis. Dig Dis Sci, 57, 2184-94.

Howden CW and Hunt RH (1987). Relationship between gastric secretion and infection. Gut, 28, 96-107.

Hsing AW, McLaughlin JK, Chow WH, et al (1998). Risk factors for colorectal cancer in a prospective study among U.S. white men. Int J Cancer, 77, 549-53.

Jones M, Helliwell P, Pritchard C, et al (2007).Helicobacter pylori in colorectal neoplasms: is there an a etiological relationship? World J Surg Oncol, 5, 51.

Kado S, Uchida K, Funabashi H, et al (2001). Intestinal microfloras are necessary for development of spontaneousadenocarcinoma of the large intestine in T-cell receptor beta chain and p53 double-knockout mice. Cancer Res, 61, 2395- 8.

Kirati Poomphakwaen, Supannee Promthet, Krittika Suwanrungruang, et al (2015). Risk Factors for Colorectal Cancer in Thailand. Asian Pac J Cancer Prev, 16, 6105-09.

Lin YL, Chiang JK, Lin SM, et al (2010). Helicobacter pylori infection concomitant with metabolic syndrome further increase risk of colorectal adenomas. World J Gastroenterol, 16, 3841- 6.

Moore WE, Moore LH (1995). Intestinal floras of populations 

that have a high risk of colon cancer. Appl Environ Microbiol, 61, 3202- 7 .

National Cancer Institute (2012). Cancer in Bangkok Thailand. 6, 2004-2006,

Penman ID, el-Omar E, Ardill JE, et al (1994). Plasma gastrin concentrations are normal in patients with colorectal neoplasia and unaltered following tumor resection. Gastroenterol, 106, 1263-70.

Pitulak Aswakul, Varayu Prachayakul1, Varut Lohsiriwat, et al (2012). Screening colonoscopy from a large single center of Thailand: Something needs to be changed? Asian Pac J Cancer Prev, 13, 1361- 4.

Shmuely H, Passaro D, Figer A, et al (2001). Relationship between Helicobacter pylori CagA status and colorectal cancer. Am J Gastroenterol, 96, 3406- 10.

Taweesak T, Soraya K, Natthawut K, et al (2015). Correlation between Gastric Mucosal Morphologic Patterns and Histopathological Severity of Helicobacter pylori Associated Gastritis Using Conventional Narrow Band Imaging Gastroscopy. Biomed Res Int, 7, 42-8.

Thorens J, Froehlich F, Schwizer W, et al (1996). Bacterial overgrowth during treatment with omeprazole compared with cimetidine: a prospective randomized double blind study. Gut, 39, 54- 9 .

Thorburn CM, Friedman GD, et al (1998). Gastrin and colorectal cancer: a prospective study. Gastroenterol, 115, 275-80.

Uchida T, Miftahussurur M, Pittayanon R, et al (2015). Helicobacter pylori Infection in Thailand: A Nationwide Study of the CagA Phenotype. PLOS ONE, 10,9.

Visek WJ (1978). Diet and cell growth modulation by ammonia. Am J Clin Nutr, 31, 216-20.

Wang F, Sun MY, Shi SL, et al (2014). Helicobacter pylori infection and normal colorectal mucosa-adenomatous polyp-adenocarcinoma sequence: a meta-analysis of 27 case-control studies. Colorectal Dis, 16, 246-52.

Wang J, Zhao Y, Jiang J, et al (2010). Polymorphisms in DNA repair genes XRCC1, XRCC3 and XPD, and colorectal cancer risk: A case-control study in an Indian population. $J$ Cancer Res Clin Oncol, 136, 1517-25.

William R, Brown, Dennis J, et al (2015). The international health care burden of cancers of the gastrointestinal tract and liver. Cancer Research Frontiers, 1, 1-9.

Zhao YS, Wang F, Chang D, et al (2008). Meta-analysis of different test indicators: Helicobacter pylori infection and the risk of colorectal cancer. Int J Colorectal Dis, 23, 875-882.

Zumkeller N, Brenner H, Zwahlen M, et al (2006). Helicobacter pylori infection and colorectal cancer risk:a meta-analysis. Helicobacter, 11, 75-80.

Zumkeller N, Brenner H, Zwahlen M, et al (2006).Helicobacter pylori infection and colorectal cancer risk: a meta-analysis. Helicobacter, 11, 75-80. 